\title{
GROWTH PERFORMANCE OF Azadirachta indica A. Juss PROVENANCES IN THE DRY ZONE OF SRI LANKA
}

\author{
${ }^{1} K A$ Kumudinie, ${ }^{2} \mathrm{DKNG}$ Pushpakumara and ${ }^{3}$ NDR Weerawardhane \\ ${ }^{1}$ Dept of Export Agriculture, Faculty of Agricultural Sciences, \\ Sabaragamuwa University of Sri Lanka, Blihulaoya \\ ${ }^{2}$ Department of Crop Science, Faculty of Agriculture, \\ University of Peradeniya, Peradeniya \\ ${ }^{3}$ Forest Research Institute, Kumbalpola
}

\begin{abstract}
Azadirachta indica A. Juss (Neem) is a multipurpose tree whose leaves, fruits, seeds and trunk produce various products for industrial and domestic uses. Although it has attracted the special interest of many researchers and has been popularized among farmers by various institutes, little has been done to provide suitable planting materials according to the farmers' requirements. Identification of highly productive individuals is very important to produce suitable planting materials. Provenance testing is the first step in this regard.

Nine introduced and two locally collected $A$. indice provenances were established at Forest Department Research Station, Korakahawewa, Anuradhapura in 1995 to evaluate growth performances. The growth and development of those provenances were assessed by using nine parameters, namely survival rate, diameter growth at breast height (DBH), height to the first branch, bark thickness, bark surface, stem straightness, resistance to shoot borer attack and branching habit at four years after its establishment. Mid ranking of significant growth and development parameters were used to identify best cverall performers.

Results of the study revealed that provenances are varied for growth and development parameters. The best $\mathrm{DBH}$ and height growth with $100 \%$ survival of plants were recorded for provenance Ban Huaysai Tai from Thailand: Proverance Rajanpur from Pakistan showed the second highest DBH and height growth with $100 \%$ sarvival. The second highest rank for stem straightness was also recorded for Rajanpur provenance. Provenance Rahimyar Khan from Pakistan is highly resistant to shoot borer attack with good ranks for other tested parameters.

Overall mid ranking of all provenances for the significant growth and development parameters measured showed that provenances of Rahimyar Khan, Rajanpur, (Pakistan), Ban Huaysai Tai (Thailand) and Kataragama (Sri Lanka) were superior to all other tested provenances at the end of four years of growth. Future implications of the results are also discussed in this paper.
\end{abstract}

